\title{
Effect of EEG Neurofeedback Training in Patients with Moderate-Severe Traumatic Brain Injury: A Clinical and Electrophysiological Outcome Study
}

\author{
Rajnish K. Gupta1, Mohammed Afsar ${ }^{1}$, Rohit K. Yadav1, Dhaval P. Shukla², and Jamuna \\ Rajeswaran ${ }^{*}$ \\ ${ }^{1}$ Department of Clinical Psychology, National Institute of Mental Health and Neuro Sciences, Bengaluru, India \\ ${ }^{2}$ Department of Neurosurgery, National Institute of Mental Health and Neuro Sciences, Bengaluru, India
}

\begin{abstract}
Traumatic brain injury (TBI) is a leading cause of death, and its survivors with a disability are considered to be an important global health priority. In view of a diverse range of disability and its impact on TBI survivors, the need for effective rehabilitation modalities is on a high rise. Therefore, the present study was aimed to investigate the efficacy of EEG neurofeedback training (EEG-NFT) in moderate-severe TBI patients on their clinical and electrophysiological outcomes. The study was an experimental longitudinal design with a pre-post comparison. A total of $14 \mathrm{TBI}$ patients in a postinjury period between 3 months to 2 years were recruited. All participants received twenty sessions of EEG-NFT. Baseline and post-NFT comparisons were made on postconcussion symptoms (PCS) and electrophysiological variables. The result indicates a significant reduction in the severity of PCS following EEG-NFT. A consistent pattern of reduced slow waves and fast waves amplitude ratios was also noted at post-NFT, although it was not significant across all the brain regions. The present study suggests EEGNFT as a contributing factor in improving PCS and normalization of qEEG in TBI patients, which holds an implication for clinical decision-making of EEG-NFT as a viable alternative to be offered to TBI patients.
\end{abstract}

Keywords: neurofeedback; traumatic brain injury; EEG; postconcussion symptoms; electrophysiology

Citation: Gupta, R. K., Afsar, M., Yadav, R. K., Shukla, D. P., \& Rajeswaran, J. (2020). Effect of EEG neurofeedback training in patients with moderate-severe traumatic brain injury: A clinical and electrophysiological outcome study. NeuroRegulation, 7(2), 75-83. https://doi.org/10.15540/nr.7.2.75

*Address correspondence to: Dr. Jamuna Rajeswaran, 306, 3rd floor, Dr. MVG Centre, Department of Clinical Psychology, National Institute of Mental Health and Neuro Sciences (NIMHANS), Hosur Road, Bengaluru-560029, India. Email: drjamunarajan@gmail.com

Copyright: () 2020. Gupta et al. This is an Open Access article distributed under the terms of the Creative Commons Attribution License (CC-BY).

\section{Edited by:}

Rex L. Cannon, PhD, SPESA Research Institute, Knoxville, Tennessee, USA

\section{Reviewed by:}

Rex L. Cannon, PhD, SPESA Research Institute, Knoxville, Tennessee, USA

Randall Lyle, PhD, Mount Mercy University, Cedar Rapids, lowa, USA

\section{Introduction}

Traumatic brain injury (TBI) disrupts the normal functioning of the brain caused by a bump, blow, or jolt to the head (Marr \& Coronado, 2004). It is a major concern worldwide, also referred to as "The Silent Epidemic" (Rusnak, 2013; Vaishnavi, Rao, \& Fann, 2009). The global incidence of TBI is estimated to be 69 million individuals per year (Dewan et al., 2018). In India, it is estimated that annually approximately 1.6 million individuals sustain a TBI (Gururaj, 2002). The prevalence of TBI increased by $8.4 \%$ from 1990 to 2016 and accounts for a considerable portion of the global injury burden (GBD 2016 TBI and SCI Collaborators, 2019). The major etiological factors of $\mathrm{TBI}$ are road traffic accidents (60\%), falls (20-25\%), and violence (10\%; Gururaj, 2002). From 2003 to 2013, in India road accidents have increased by $5 \%$ per year while the population increased by $1.4 \%$ per year, suggesting a high prevalence of TBI (Singh, 2017).

TBI results in a large number of deaths or survivors with impairments in a wide array of cognitive domains such as executive functions (Azouvi et al., 2016), processing speed (Fong, Chan, $\mathrm{Ng}, \& \mathrm{Ng}$, 2009), response inhibition (Dimoska-Di Marco, McDonald, Kelly, Tate, \& Johnstone, 2011), memory 
(West, Curtis, Greve, \& Bianchini, 2011; Wright, Schmitter-Edgecombe, \& Woo, 2010), and social cognition (Spikman, Timmerman, Milders, Veenstra, \& van der Naalt, 2012). These impairments ascend to the behavioral, cognitive, emotional, and physical changes that affect a person's quality of life (QOL; Langlois, Rutland-Brown, \& Wald, 2006). The cognitive functioning was found impaired in moderate-severe TBI patients even after two years postinjury (Schretlen \& Shapiro, 2003). Postconcussion symptoms (PCS) are the most commonly reported sequelae of $\mathrm{TBI}$, which include headache, dizziness, fatigue, temper, sleep disturbance, memory problems, blurred vision, poor concentration, anxiety, and irritability (Dikmen, Machamer, Fann, \& Temkin, 2010; McLean, Dikmen, Temkin, Wyler, \& Gale, 1984; Stålnacke, 2012). A significant range of psychiatric disorders such as depression, generalized anxiety disorder, posttraumatic stress disorder, and agoraphobia are found to be associated with posttraumatic injury (Bryant et al., 2010). Population-based studies report that patients with post-head-injury are more liable to develop epilepsy and a binge pattern of alcohol use (Christensen, 2012; Ferguson et al., 2010; Horner et al., 2005).

The consequences of TBI are not only circumscribed to these overt changes and dysfunctions but also lead to the disruptions and alterations of brain function, including changes in electrophysiological patterns. These alterations have been found to be associated with poor functional outcomes. EEG abnormalities can be focal, multifocal, or widespread depending upon the severity and location of the injury (Brigo \& Mecarelli, 2019; Galovic, Schmitz, \& Tettenborn, 2018). A considerable amount of studies has been shown to correspond to quantitative EEG (qEEG) changes after the concussion. The most common $\mathrm{qEEG}$ findings of persons with mild TBI (mTBI) are attenuated alpha frequency in the posterior region and increased theta activity (Arciniegas, 2011; Lewine et al., 2019; Nuwer, Hovda, Schrader, \& Vespa, 2005; Tebano et al., 1988; Thatcher, Walker, Gerson, \& Geisler, 1989). Acute disruption of cortical-thalamic networks led to an increase in delta and theta band and a decrease in beta band in TBI (Moeller, Tu, \& Bazil, 2011). A consequential higher theta-alpha, theta-beta, and delta-alpha amplitude ratio and minimized EEG coherence were also noted in mTBI (Chen, Tao, \& Chen, 2006; Modarres, Kuzma, Kretzmer, Pack, \& Lim, 2016; Moeller et al., 2011; Watson et al., 1995). An epileptiform activity has been observed immediately followed by a diffuse slowing of the EEG after head injury (Walker, Kollros, \& Case, 1945).

With a diverse range of disability and its impact on TBI survivors, new intervention modalities are being attempted to address the TBI-related issues. One of such modalities is EEG neurofeedback training (EEG-NFT) that uses electrophysiological measures of an individual to self-regulate their psychophysiological state (Ali, Viczko, \& Smart, 2020). It is a noninvasive and nonpharmacological intervention based on the principles of operant conditioning. EEG-NFT has shown promising effects for ameliorating cognitive, behavioral, emotional, and physical dysfunctions among patients with TBI (Bennett et al., 2018; Keller, 2001; Munivenkatappa, Rajeswaran, Indira Devi, Bennet, \& Upadhyay, 2014; Reddy, Rajeswaran, Devi, \& Kandavel, 2013; Schoenberger, Shiflett, Esty, Ochs, \& Matheis, 2001).

There are very limited to no studies being attempted of investigating clinical and electrophysiological changes in the moderate-severe TBI following EEGNFT. Therefore, the present study uses the alpha reinforcement and theta inhibition training with the aim to reduce theta-alpha amplitude ratio to explore the electrophysiological alterations and the subsequent consequences on PCS among patients with moderate-severe TBI.

\section{Methods and Materials}

\section{Participants}

The sample comprised of 19 individuals (15 males and 4 females) diagnosed with TBI with normal or corrected hearing and vision in the age range of 1850 years (mean age $=32.47$ years; $S D=7.52$ ). All participants with TBI had a Glasgow Coma Scale (GCS) score 12 or less with a postinjury period between 3 months to 2 years.

Participants with a diagnosis of mTBI (GCS: 13-15), with extracranial injuries, having a previous history of any comorbid neurological, psychiatric, or neurosurgical conditions, substance dependence, or mental retardation, and those who underwent any form of structured psychological intervention in the last year were excluded.

\section{Procedure}

After obtaining ethical clearance from the Institute Ethics Committee, a written informed consent form was sought from each participant who met inclusion criteria. Sociodemographic and clinical details were obtained, and baseline assessments were 
conducted using the Rivermead Postconcussion Symptoms Questionnaire (RPQ) and a resting-state eyes-opened EEG recording. Following the baseline, all the participants received 20 sessions of EEG-NFT (those who completed $80 \%$ of sessions were also considered as completers). To examine the posttraining effect, the same baseline assessments were readministered immediately after the completion of EEG-NFT.

\section{Rivermead Postconcussion Symptoms Questionnaire. It was used to assess the severity of the symptoms reporting in the postinjury period. It consists of 16 items assessing the most commonly reported PCS. The scores ranged from $0-4$ where 0 indicates the symptoms were not experienced, 1 as the symptom was no more a problem, 2 as a mild problem, 3 as a moderate problem, and 4 as a severe problem. The participants were asked to rate the degree to which they experienced the symptoms. The total score represented the overall severity of PCS.}

EEG recording. The EEG was conducted in a dimly lit, sound-attenuated room while the patient was seated comfortably. The recording was performed using SynAmps amplifiers (Compumedics Neuroscan, Charlotte, $\mathrm{NC}$ ) with $32 \mathrm{Ag} / \mathrm{AgCl}$, passive electrodes, fitted in the lycra stretch cap. Sampling frequency was kept at $1 \mathrm{kHz}$ with a notch filter at 50 $\mathrm{Hz}$. For eye movement, horizontal and vertical electrooculograms (EOG) were used bipolarly. One electrode on each mastoid was used as a reference. Electrodes impedance was ascertained less than 10 $k \Omega$.

Intervention. The participants received 20 sessions of EEG-NFT conducted three times a week spanning the whole intervention program over a period of 2 months. It was carried out in a quiet, dimly lit room using a dedicated NFT system (Atlantis system, BrainMaster Technologies, Inc., Bedford, $\mathrm{OH}$ ). Each participant received alpha-theta training (reinforcing alpha and inhibiting theta) activity with the aim of reducing the theta-alpha amplitude ratio. The active sites were fixed at $\mathrm{O} 1$ and $\mathrm{O} 2$ locations as per the 10-20 International system, each reference electrode on mastoid, and the ground electrode on the forehead. An abrasive gel was used to clean and prepare the scalp/skin followed by mounting the electrode using a conductive paste. Before the procedure, the goal and nature of the task were explained thoroughly to the participant. The display screen was selected as per the participants' choice. The participants were instructed to relax and focus on the screen. The reward was given through visual feedback (i.e., an increase in the score), which is displayed on the screen. Each NFT session lasted for 40-min duration. The training was done under the supervision of a trained clinical neuropsychologist (as per the norms of the rehabilitation council of India).

Data analysis. EEG data were analyzed using Neuroscan v4.5 (Compumedics Neuroscan, Charlotte, NC). Finite impulse response (FIR) bandpass filter from 0.1 to $30 \mathrm{~Hz}$ with a zero-phase shift at $12 \mathrm{~dB} /$ octave was applied to retain all relevant frequencies. For eye movement and other artifacts corrections, EEG data were marked manually, and spatial filter transformation was performed through principal component analysis (PCA) using singular value decomposition (SVD). Spectral analysis was performed on artifact-free data using 1024 data points. The signals from all the electrode positions underwent the fast Fourier transformation (FFT) on 500 ms epochs with a Hanning window of $1024 \mathrm{~Hz}$. The resulting frequency spectra were divided into frequency band of interest: delta $(0.1-3.0 \mathrm{~Hz})$, theta $(4-7 \mathrm{~Hz})$, alpha $(8-12 \mathrm{~Hz})$, beta $(13-30 \mathrm{~Hz})$.

Further statistical analyses were carried out on SPSS v20.0. To check the normality for all values of interest Shapiro-Wilk test was performed (Shapiro \& Wilk, 1965). The data group that was normally distributed a paired $t$-test was performed, while for the data that violated the normality assumption, a similar nonparametric Wilcoxon signed-rank test was used. A statistical significance threshold was set at $p<.05$.

\section{Results}

From the 19 participants with TBI who were recruited for EEG-NFT, two participants dropped out (did not turn up for sessions after baseline assessment or did not complete up to $80 \%$ of the sessions). From the remaining 17 participants, three patients could not complete baseline and/or post-NFT assessments.

\section{Rivermead Postconcussion Symptoms Questionnaire (RPQ)}

The RPQ-total score which forms the severity of TBI symptoms significantly reduced $(p=.018)$ in postNFT compared to the baseline. The effect size within-subjects also showed a medium effect (0.725) on RPQ-T scores (Table 1; Figure 1). 


\section{Table 1}

Rivermead Postconcussion Symptoms Questionnaire total (RPQ-T) score $(n=14)$.

\begin{tabular}{|c|c|c|c|c|c|}
\hline S. No. & Variable & $\begin{array}{c}\text { Baseline } \\
(\text { Mean } \pm S D)\end{array}$ & $\begin{array}{c}\text { Post-NFT } \\
(\text { Mean } \pm S D)\end{array}$ & $p$ Value & $\begin{array}{l}\text { Effect Size } \\
\text { Cohen's } d\end{array}$ \\
\hline
\end{tabular}

$\begin{array}{llllll} & \text { RPQ-T } & 16.57 \pm 10.523 & 10.29 \pm 9.587 & .018^{*} & 0.725\end{array}$

Note. * Significance at 0.05 level.

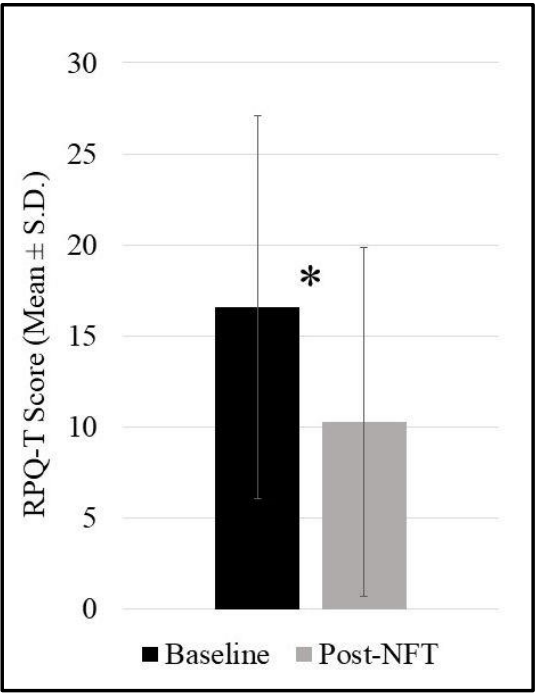

Figure 1. Rivermead Postconcussion Symptoms Questionnaire total (RPQ-T) score at baseline and post-NFT $(n=14)$.

\section{EEG Neurofeedback Training (EEG-NFT)}

For the EEG-NFT sessions, a ratio of an average amplitude of theta and alpha frequency bands was calculated at $\mathrm{O} 1$ and $\mathrm{O} 2$ locations in the first and last session. The result indicates that the thetaalpha ratio has reduced at both $01(p=.665)$ and O2 $(p=.011)$ locations, although this was not statistically significant at $\mathrm{O} 1$ (Table 2; Figure 2).

\section{Table 2}

Average amplitude of theta-alpha ratio at 01 and 02 locations in the first and last session $(n=14)$.

\begin{tabular}{ccccc}
\hline $\begin{array}{c}\text { S. } \\
\text { No. }\end{array}$ & Location & $\begin{array}{c}\text { First Session } \\
(\text { Mean } \pm S D)\end{array}$ & $\begin{array}{c}\text { Last Session } \\
(\text { Mean } \pm S D)\end{array}$ & $\begin{array}{c}p \\
\text { Value }\end{array}$ \\
1 & O1 & $0.967 \pm 0.265$ & $0.94 \pm 0.252$ & .665 \\
2 & O2 & $1.06 \pm 0.302$ & $0.914 \pm 0.28$ & $.011^{*}$ \\
\hline
\end{tabular}

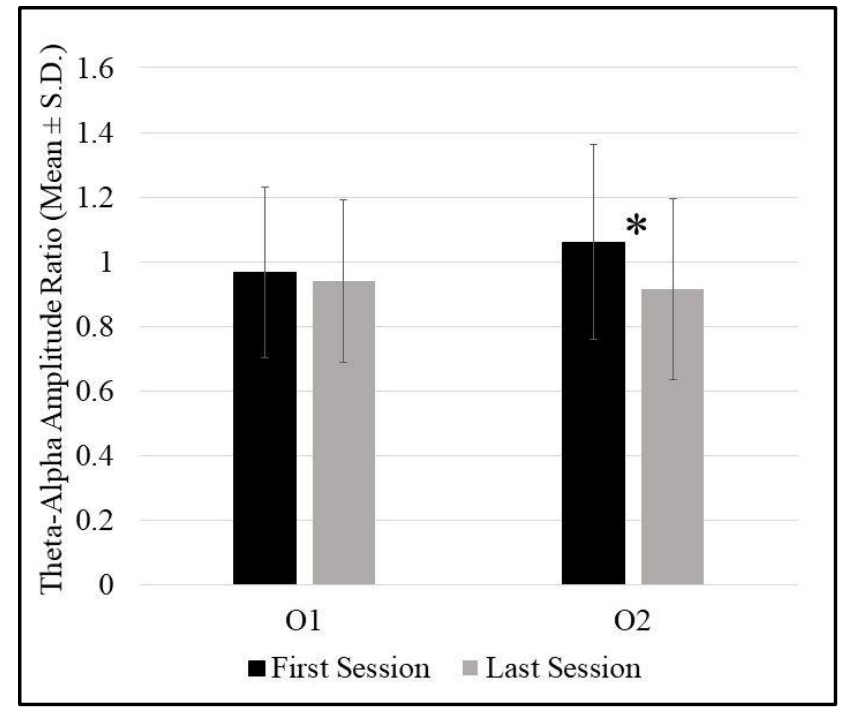

Figure 2. The average amplitude of theta-alpha ratio at $\mathrm{O} 1$ and $\mathrm{O} 2$ locations in the first and last session $(n=14)$.

\section{EEG Analysis}

For each electrode, EEG amplitude values were averaged across the participants. Further, these electrodes were grouped into five different brain regions to examine the regional differences in EEG amplitude. An average score of the individual electrode in that region formed the score for each region (Figure 3 ).

Note. * Significance at 0.05 level. 


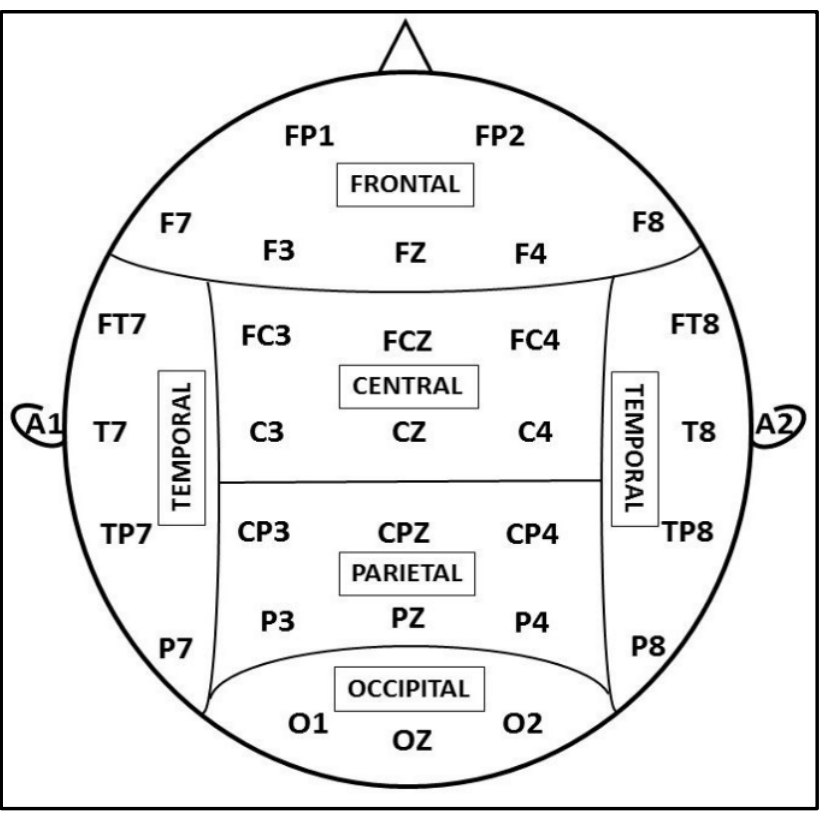

Figure 3. 32-electrodes were grouped into five brain regions (frontal, central, temporal, parietal, and occipital) as per 10-20 system.

A consistent pattern of a reduced delta-alpha, thetaalpha, and theta-beta ratios ratio was observed across all the brain regions in post-NFT compared to the baseline. Although this was statistically significant only in the temporal $(p=.041)$ and central $(p=.038)$ regions for delta-alpha and in the occipital $(p=.033)$ for theta-alpha (Table 3; Figure 4).

\begin{tabular}{|c|c|c|c|c|}
\hline \multicolumn{5}{|c|}{$\begin{array}{l}\text { Table } 3 \\
\text { Average EEG amplitude of delta-alpha, theta-alpha, } \\
\text { and theta-beta ratio at baseline and post-NFT ( } n= \\
\text { 14). }\end{array}$} \\
\hline $\begin{array}{l}\text { S. } \\
\text { No. }\end{array}$ & Variable & $\begin{array}{c}\text { Baseline } \\
\text { (Mean } \pm S D)\end{array}$ & $\begin{array}{c}\text { Post-NFT } \\
(\text { Mean } \pm S D)\end{array}$ & $\begin{array}{c}p \\
\text { Value }\end{array}$ \\
\hline 1 & $\begin{array}{l}\text { Occipital } \\
\text { delta- } \\
\text { alpha }\end{array}$ & $0.283 \pm 0.059$ & $0.275 \pm 0.064$ & .599 \\
\hline 2 & $\begin{array}{l}\text { Parietal } \\
\text { delta- } \\
\text { alpha }\end{array}$ & $0.267 \pm 0.075$ & $0.247 \pm 0.069$ & .122 \\
\hline 3 & $\begin{array}{l}\text { Temporal } \\
\text { delta- } \\
\text { alpha }\end{array}$ & $0.313 \pm 0.065$ & $0.284 \pm 0.073$ & $.041^{*}$ \\
\hline 4 & $\begin{array}{l}\text { Central } \\
\text { delta- } \\
\text { alpha }\end{array}$ & $0.291 \pm 0.086$ & $0.27 \pm 0.078$ & $.038^{*}$ \\
\hline 5 & $\begin{array}{l}\text { Frontal } \\
\text { delta- } \\
\text { alpha }\end{array}$ & $0.363 \pm 0.074$ & $0.331 \pm 0.08$ & .054 \\
\hline 6 & $\begin{array}{l}\text { Occipital } \\
\text { theta- } \\
\text { alpha }\end{array}$ & $1.319 \pm 0.399$ & $1.184 \pm 0.377$ & $.033^{*}$ \\
\hline 7 & $\begin{array}{l}\text { Parietal } \\
\text { theta- } \\
\text { alpha }\end{array}$ & $1.186 \pm 0.281$ & $1.17 \pm 0.319$ & .826 \\
\hline 8 & $\begin{array}{l}\text { Temporal } \\
\text { theta- } \\
\text { alpha }\end{array}$ & $1.088 \pm 0.452$ & $0.97 \pm 0.346$ & .113 \\
\hline 9 & $\begin{array}{l}\text { Central } \\
\text { theta- } \\
\text { alpha }\end{array}$ & $1.201 \pm 0.449$ & $1.118 \pm 0.406$ & .136 \\
\hline 10 & $\begin{array}{l}\text { Frontal } \\
\text { theta- } \\
\text { alpha }\end{array}$ & $1.537 \pm 0.371$ & $1.432 \pm 0.409$ & .111 \\
\hline 11 & $\begin{array}{l}\text { Occipital } \\
\text { theta- } \\
\text { beta }\end{array}$ & $2.357 \pm 1.067$ & $2.244 \pm 0.665$ & .603 \\
\hline 12 & $\begin{array}{l}\text { Parietal } \\
\text { theta- } \\
\text { beta }\end{array}$ & $2.712 \pm 1.265$ & $2.597 \pm 1.356$ & .440 \\
\hline 13 & $\begin{array}{l}\text { Temporal } \\
\text { theta- } \\
\text { beta }\end{array}$ & $3.005 \pm 1.287$ & $2.699 \pm 1.359$ & .062 \\
\hline 14 & $\begin{array}{l}\text { Central } \\
\text { theta- } \\
\text { beta }\end{array}$ & $2.831 \pm 1.388$ & $2.726 \pm 1.445$ & .430 \\
\hline 15 & $\begin{array}{l}\text { Frontal } \\
\text { theta- } \\
\text { beta }\end{array}$ & $3.141 \pm 1.38$ & $2.953 \pm 1.523$ & .302 \\
\hline
\end{tabular}

Note. ${ }^{*}$ Significance at 0.05 level. 


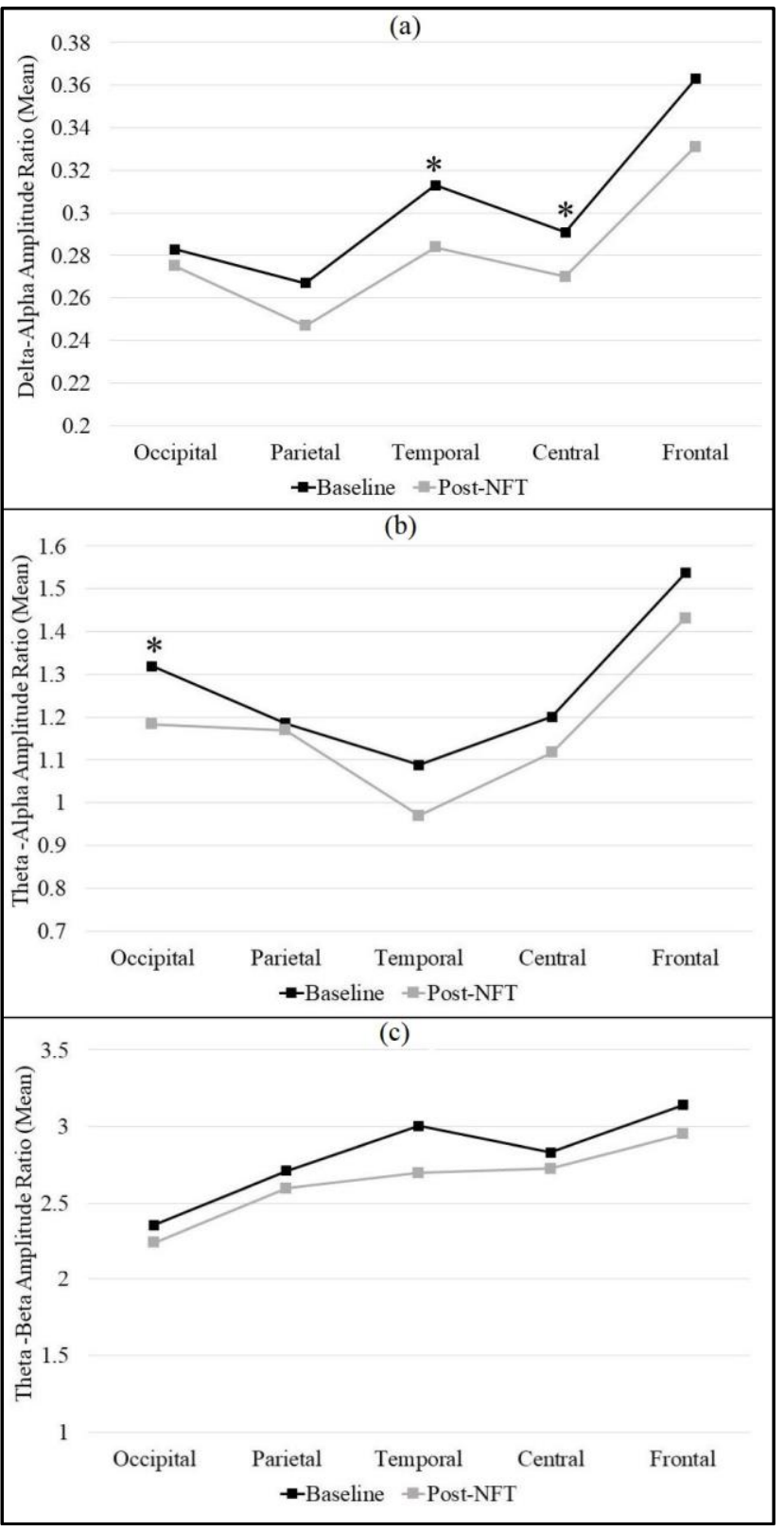

Figure 4. The average EEG amplitude of (a) delta-alpha, (b) theta-alpha, and (c) theta-beta ratios at baseline and post-NFT $(n=14)$.

\section{Discussion}

The current study investigated the efficacy of EEGNFT in patients with moderate-severe TBI on their clinical and electrophysiological outcomes. Participants were assessed at baseline and postNFT using Rivermead Postconcussion Symptoms Questionaire total (RPQ-T) score and EEG amplitude.

\section{Effectiveness of EEG-NFT on Clinical Outcome}

The findings from the study indicate a significant reduction in the severity of PCS on the RPQ-T score. These findings are in line with previous studies showing that EEG-NFT leads to a significant decrease in PCS (Rajeswaran, Bennett, Thomas, \& Rajakumari, 2013; Reddy et al., 2013). A study by Reddy et al. suggested a negative correlation of RPQ with QOL and neuropsychological functioning (Reddy, Rajeswaran, Devi, \& Kandavel, 2017). Therefore, the reduction of PCS on RPQ-T might contribute to improving $\mathrm{QOL}$ and cognitive functioning in patients with TBI, which is corroborated by earlier studies (Bennett, Sampath, Christopher, Thennarasu, \& Rajeswaran, 2017; Hoffman, Stockdale, \& van Egren, 1996; Munivenkatappa et al., 2014; Reddy, Rajeswaran, Bhagavatula, \& Kandavel, 2014).

\section{Effectiveness of EEG-NFT on the \\ Electrophysiological Outcome}

EEG amplitude ratio is potentially an important indicator of cognitive ability (Trammell, MacRae, Davis, Bergstedt, \& Anderson, 2017) and constitutes a more reliable index to monitor electrophysiological alterations over time in TBI (Álvarez et al., 2008). The qEEG data reported herein suggest a consistent pattern of reduced slow waves and fast waves (SW/FW) amplitude ratios at post-NFT. Although significant changes were observed only for deltaalpha in the temporal and central regions and for theta-alpha in the occipital region.

A positive association of cognitive deterioration has been found with an increased SW/FW ratio in patients with moderate-severe TBI (Álvarez et al., 2008). A study by Leon-Carrion et al. indicates a negative correlation between delta-alpha ratio and functional outcome in patients with head injury (Leon-Carrion, Martin-Rodriguez, Damas-Lopez, Barroso y Martin, \& Dominguez-Morales, 2009). An increased theta-beta ratio has been related to higher impulsive behavior (van Dongen-Boomsma et al., 2010) and lower response inhibition (Putman, van Peer, Maimari, \& van der Werff, 2010). Therefore, a reduction in the SW/FW amplitude ratio might be related to better cognitive functioning (Álvarez et al., 2008) and could be attributed to significantly reduced PCS observed in our study.

These qEEG changes can be suggested by modulation in thalamo-cortical networks that refines the intrinsic neural network, led to the normalization of qEEG pattern in TBI following EEG-NFT (Munivenkatappa et al., 2014). Since, SW/FW amplitude values negatively correlate with cerebral 
blood flow and brain metabolism functioning (Coles et al., 2004; Nagata, Tagawa, Hiroi, Shishido, \& Uemura, 1989), a reduction in SW/FW values might be associated with a recovery of the brain metabolism in TBI (Álvarez et al., 2008).

The findings from the EEG-NFT sessions indicate that qEEG changes were not due to chance, as there were progressive changes in qEEG across NFT sessions. It is also worthwhile noticing that electrophysiological changes in the present study were marked 3 months to 2 years of postinjury, suggesting that these changes were not concomitant by the time.

To conclude, the findings suggest EEG-NFT as a contributing factor in improving postconcussion symptoms and normalization of qEEG in patients with moderate-severe TBI. The present study also holds an implication for clinical decision-making of EEG-NFT as a viable alternative to be offered to patients with moderate-severe TBI. The limitations of the present study are the small sample size, limited variables, and lack of control group. Accounting together these limitations affect the generalizability of the study. Therefore, future research would require structural, functional, biochemical, and cognitive correlates on a larger cohort following the intervention.

\section{Acknowledgements}

The authors thank all the participants who gave consent for this study. We also thank Mr. Deepak R. Ullal, Senior Technician, for providing the required technical support during the EEG recordings.

\section{Author Disclosure}

No potential conflict of interest is reported by the authors. This study was supported by the Science and Engineering Research Board (SERB), Department of Science and Technology (DST), Ministry of Science and Technology, India, and partially supported by the Foundation for Neurofeedback and Neuromodulation Research (FNNR), USA.

\section{References}

Ali, J. I., Viczko, J., \& Smart, C. M. (2020). Efficacy of neurofeedback interventions for cognitive rehabilitation following brain injury: Systematic review and recommendations for future research. Journal of the International Neuropsychological Society, 26(1), 31-46. https://doi.org/10.1017/S1355617719001061

Álvarez, X. A., Sampedro, C., Figueroa, J., Tellado, I., González, A., García-Fantini, M., ... Moessler, H. (2008). Reductions in qEEG slowing over 1 year and after treatment with Cerebrolysin in patients with moderate-severe traumatic brain injury. Journal of Neural Transmission (Vienna), 115(5), 683-692. https://doi.org/10.1007/s00702-008-0024-9

Arciniegas, D. B. (2011). Clinical electrophysiologic assessments and mild traumatic brain injury: State-of-the-science and implications for clinical practice. International Journal of Psychophysiology, 82(1), 41-52. https://doi.org/10.1016 /j.jpsycho.2011.03.004

Azouvi, P., Vallat-Azouvi, C., Joseph, P.-A., Meulemans, T., Bertola, C., Le Gall, D., ... GREFEX Study Group. (2016). Executive functions deficits after severe traumatic brain injury: The GREFEX study. Journal of Head Trauma Rehabilitation, 31(3), E10-E20. https://doi.org/10.1097 /HTR.0000000000000169

Bennett, C. N., Gupta, R. K., Prabhakar, P., Christopher, R. Sampath, S., Thennarasu, K., \& Rajeswaran, J. (2018). Clinical and biochemical outcomes following EEG neurofeedback training in traumatic brain injury in the context of spontaneous recovery. Clinical EEG and Neuroscience, 49(6), 433-440. https://doi.org/10.1177/1550059417744899

Bennett, C. N., Sampath, S., Christopher, R., Thennarasu, K., \& Rajeswaran, J. (2017). Effect of electroencephalogram neurofeedback training on quality of life in patients with traumatic brain injury: In context of spontaneous recovery. Indian Journal of Neurotrauma, 14(02/03), 129-134. https://doi.org/10.1055/s-0038-1649280

Brigo, F., \& Mecarelli, O. (2019). Traumatic Brain Injury. In O. Mecarelli (Ed.), Clinical Electroencephalography (pp. 617622). Switzerland: Springer International Publishing.

Bryant, R. A., O'Donnell, M. L., Creamer, M., McFarlane, A. C. Clark, C. R., \& Silove, D. (2010). The psychiatric sequelae of traumatic injury. The American Journal of Psychiatry, 167(3), 312-320. https://doi.org/10.1176/appi.ajp.2009.09050617

Chen, X.-P., Tao, L.-Y., \& Chen, A. C. N. (2006). Electroencephalogram and evoked potential parameters examined in Chinese mild head injury patients for forensic medicine. Neuroscience Bulletin, 22(3), 165-170.

Christensen, J. (2012). Traumatic brain injury: Risks of epilepsy and implications for medicolegal assessment. Epilepsia, 53(S4), 43-47. https://doi.org/10.1111/j.15281167.2012.03612.x

Coles, J. P., Steiner, L. A., Johnston, A. J., Fryer, T. D., Coleman, M. R., Smieleweski, P., ... Menon, D. K. (2004). Does induced hypertension reduce cerebral ischaemia within the traumatized human brain? Brain, 127(11), 2479-2490. https://doi.org/10.1093/brain/awh268

Dewan, M. C., Rattani, A., Gupta, S., Baticulon, R. E., Hung, Y.C., Punchak, M., ... Park, K. B. (2018). Estimating the global incidence of traumatic brain injury. Journal of Neurosurgery, 130(4), 1080-1097. https://doi.org/10.3171 /2017.10.JNS17352

Dikmen, S., Machamer, J., Fann, J. R., \& Temkin, N. R. (2010). Rates of symptom reporting following traumatic brain injury. Journal of the International Neuropsychological Society, 16(3), 401-411. https://doi.org/10.1017/S1355617710000196

Dimoska-Di Marco, A., McDonald, S., Kelly, M., Tate, R., \& Johnstone, S. (2011). A meta-analysis of response inhibition and Stroop interference control deficits in adults with traumatic brain injury (TBI). Journal of Clinical and Experimental Neuropsychology, 33(4), 471-485. https://doi.org/10.1080/13803395.2010.533158

Ferguson, P. L., Smith, G. M., Wannamaker, B. B., Thurman, D. J., Pickelsimer, E. E., \& Selassie, A. W. (2010). A populationbased study of risk of epilepsy after hospitalization for traumatic brain injury. Epilepsia, 51(5), 891-898. https://doi.org/10.1111/j.1528-1167.2009.02384.x

Fong, K. N. K., Chan, M. K. L., Ng, P. P. K., \& Ng, S. S. W. (2009). Measuring processing speed after traumatic brain injury in the outpatient clinic. NeuroRehabilitation, 24(2), 165173. https://doi.org/10.3233/NRE-2009-0465 
Galovic, M., Schmitz, B., \& Tettenborn, B. (2018). EEG in inflammatory disorders, cerebrovascular diseases, trauma and migraine. In D. L. Schomer \& F. H. Lopes da Silva (Eds.), Niedermeyer's electroencephalography: basic principles, clinical applications, and related fields (7th ed., pp. 371-412). Oxford: Oxford University Press. https://doi.org $/ 10.1093 / \mathrm{med} / 9780190228484.003 .0015$

GBD 2016 Traumatic Brain Injury and Spinal Cord Injury Collaborators. (2019). Global, regional, and national burden of traumatic brain injury and spinal cord injury, 1990-2016: A systematic analysis for the Global Burden of Disease Study 2016. The Lancet Neurology, 18(1), 56-87. https://doi.org /10.1016/S1474-4422(18)30415-0

Gururaj, G. (2002). Epidemiology of traumatic brain injuries: Indian scenario. Neurological Research, 24(1), 24-28. https://doi.org/10.1179/016164102101199503

Hoffman, D., Stockdale, S., \& van Egren, L. (1996). EEG neurofeedback in the treatment of mild traumatic brain injury. Clinical Electroencephalography, 27(2), 6.

Horner, M. D., Ferguson, P. L., Selassie, A. W., Labbate, L. A., Kniele, K., \& Corrigan, J. D. (2005). Patterns of alcohol use 1 year after traumatic brain injury: A population-based, epidemiological study. Journal of the International Neuropsychological Society, 11(3), 322-330. https://doi.org /10.1017/S135561770505037X

Keller, I. (2001). Neurofeedback therapy of attention deficits in patients with traumatic brain injury. Journal of Neurotherapy, 5(1-2), 19-32. https://doi.org/10.1300/J184v05n01_03

Langlois, J. A., Rutland-Brown, W., \& Wald, M. M. (2006). The epidemiology and impact of traumatic brain injury: A brief overview. Journal of Head Trauma Rehabilitation, 21(5), 375378. https://doi.org/10.1097/00001199-200609000-00001

Leon-Carrion, J., Martin-Rodriguez, J. F., Damas-Lopez, J., Barroso y Martin, J. M., \& Dominguez-Morales, M. R. (2009). Delta-alpha ratio correlates with level of recovery after neurorehabilitation in patients with acquired brain injury. Clinical Neurophysiology, 120(6), 1039-1045. https://doi.org /10.1016/j.clinph.2009.01.021

Lewine, J. D., Plis, S., Ulloa, A., Williams, C., Spitz, M., Foley, J., ... Weaver, L. (2019). Quantitative EEG biomarkers for mild traumatic brain injury. Journal of Clinical Neurophysiology, 36(4), 298-305. https://doi.org/10.1097 WWP.0000000000000588

Marr, A. L., \& Coronado, V. G. (Eds.) (2004). Central nervous system injury surveillance data submission standards-2002. Atlanta, GA: US Department of Health and Human Services, CDC.

McLean, A., Jr., Dikmen, S., Temkin, N., Wyler, A. R., \& Gale, J. L. (1984). Psychosocial functioning at 1 month after head injury. Neurosurgery, 14(4), 393-399. https://doi.org/10.1227 /00006123-198404000-00001

Modarres, M., Kuzma, N. N., Kretzmer, T., Pack, A. I., \& Lim, M. M. (2016). EEG slow waves in traumatic brain injury: Convergent findings in mouse and man. Neurobiology of Sleep and Circadian Rhythms, 1, S2451994416300025.

Moeller, J. J., Tu, B., \& Bazil, C. W. (2011). Quantitative and qualitative analysis of ambulatory electroencephalography during mild traumatic brain injury. Archives of Neurology, 68(12), 1595-1598. https://doi.org/10.1001 larchneurol.2011.1080

Munivenkatappa, A., Rajeswaran, J., Indira Devi, B., Bennet, N., \& Upadhyay, N. (2014). EEG neurofeedback therapy: Can it attenuate brain changes in TBI? NeuroRehabilitation, 35(3), 481-484. https://doi.org/10.3233/NRE-141140

Nagata, K., Tagawa, K., Hiroi, S., Shishido, F., \& Uemura, K. (1989). Electroencephalographic correlates of blood flow and oxygen metabolism provided by positron emission tomography in patients with cerebral infarction. Electroencephalography and Clinical Neurophysiology, 72(1), 16-30. https://doi.org/10.1016/0013-4694(89)90027-8
Nuwer, M. R., Hovda, D. A., Schrader, L. M., \& Vespa, P. M. (2005). Routine and quantitative EEG in mild traumatic brain injury. Clinical Neurophysiology, 116(9), 2001-2025. https://doi.org/10.1016/j.clinph.2005.05.008

Putman, P., van Peer, J., Maimari, I., \& van der Werff, S. (2010). EEG theta/beta ratio in relation to fear-modulated responseinhibition, attentional control, and affective traits. Biological Psychology, 83(2), 73-78. https://doi.org/10.1016 /j.biopsycho.2009.10.008

Rajeswaran, J., Bennett, C. N., Thomas, S., \& Rajakumari, K. (2013). EEG neurofeedback training in clinical conditions. Neuropsychological Rehabilitation, 57-78. https://doi.org /10.1016/B978-0-12-416046-0.00004-3

Reddy, R. P., Rajeswaran, J., Bhagavatula, I. D., \& Kandavel, T. (2014). Silent Epidemic: The effects of neurofeedback on quality-of-life. Indian Journal of Psychological Medicine, 36(1), 40-44. https://doi.org/10.4103/0253-7176.127246

Reddy, R. P., Rajeswaran, J., Devi, B. I., \& Kandavel, T. (2013). Neurofeedback training as an intervention in a silent epidemic: An Indian scenario. Journal of Neurotherapy, 17(4), 213-225. https://doi.org/10.1080/10874208.2013.847139

Reddy, R. P., Rajeswaran, J., Devi, B. I., \& Kandavel, T. (2017). Cascade of traumatic brain injury: A correlational study of cognition, postconcussion symptoms, and quality of life. Indian Journal of Psychological Medicine, 39(1), 32-39. https://doi.org/10.4103/0253-7176.198940

Rusnak, M. (2013). Traumatic brain injury: Giving voice to a silent epidemic. Nature Reviews Neurology, 9(4), 186-187. https://doi.org/10.1038/nrneurol.2013.38

Schoenberger, N. E., Shiflett, S. C., Esty, M. L., Ochs, L., \& Matheis, R. J. (2001). Flexyx Neurotherapy System in the treatment of traumatic brain injury: An initial evaluation. Journal of Head Trauma Rehabilitation, 16(3), 260-274. https://doi.org/10.1097/00001199-200106000-00005

Schretlen, D. J., \& Shapiro, A. M. (2003). A quantitative review of the effects of traumatic brain injury on cognitive functioning. International Review of Psychiatry, 15(4), 341-349. https://doi.org/10.1080/09540260310001606728

Shapiro, S. S. \& Wilk, M. B. (1965). An analysis of variance test for normality (complete samples). Biometrika, 52(3-4), 591611. https://doi.org/10.1093/biomet/52.3-4.591

Singh, S. K. (2017). Road traffic accidents in India: Issues and challenges. Transportation Research Procedia, 25, 47084719. https://doi.org/10.1016/j.trpro.2017.05.484

Spikman, J. M., Timmerman, M. E., Milders, M. V., Veenstra, W. S., \& van der Naalt, J. (2012). Social cognition impairments in relation to general cognitive deficits, injury severity, and prefrontal lesions in traumatic brain injury patients. Journal of Neurotrauma, 29(1), 101-111. https://doi.org/10.1089 /neu.2011.2084

Stålnacke, B. M. (2012). Postconcussion symptoms in patients with injury-related chronic pain. Rehabilitation Research and Practice, 2012, 528265. https://doi.org/10.1155/2012/528265

Tebano, M. T., Cameroni, M., Gallozzi, G., Loizzo, A., Palazzino, G., Pezzini, G., \& Ricci, G. F. (1988). EEG spectral analysis after minor head injury in man. Electroencephalography and Clinical Neurophysiology, 70(2), 185-189. https://doi.org /10.1016/0013-4694(88)90118-6

Thatcher, R. W., Walker, R. A., Gerson, I., \& Geisler, F. H. (1989). EEG discriminant analyses of mild head trauma Electroencephalography and Clinical Neurophysiology, 73(2), 94-106. https://doi.org/10.1016/0013-4694(89)90188-0

Trammell, J. P., MacRae, P. G., Davis, G., Bergstedt, D., \& Anderson, A. E. (2017). The relationship of cognitive performance and the theta-alpha power ratio is agedependent: An EEG study of short term memory and reasoning during task and resting-state in healthy young and old adults. Frontiers in Aging Neuroscience, 9, 364. https://doi.org/10.3389/fnagi.2017.00364 
Vaishnavi, S., Rao, V., \& Fann, J. R. (2009). Neuropsychiatric problems after traumatic brain injury: Unraveling the silent epidemic. Psychosomatics, 50(3), 198-205. https://doi.org /10.1176/appi.psy.50.3.198

van Dongen-Boomsma, M., Lansbergen, M. M., Bekker, E. M., Kooij, J. J. S., van der Molen, M., Kenemans, J. L., \& Buitelaar, J. K. (2010). Relation between resting EEG to cognitive performance and clinical symptoms in adults with attention-deficit/hyperactivity disorder. Neuroscience Letters, 469(1), 102-106. https://doi.org/10.1016/j.neulet.2009.11.053

Walker, A. E., Kollros, J. J., \& Case, T. J. (1945). The physiological basis of cerebral concussion: Trauma of the nervous system. Association for Research in Nervous and Mental Disease, 24, 437-472.

Watson, M. R., Fenton, G. W., McClelland, R. J., Lumsden, J., Headley, M., \& Rutherford, W. H. (1995). The postconcussional state: Neurophysiological aspects. The British
Journal of Psychiatry, 167(4), 514-521. https://doi.org /10.1192/bjp.167.4.514

West, L. K., Curtis, K. L., Greve, K. W., \& Bianchini, K. J. (2011). Memory in traumatic brain injury: The effects of injury severity and effort on the Wechsler Memory Scale-III. Journal of Neuropsychology, 5(1), 114-125. https://doi.org/10.1348 $1174866410 \times 521434$

Wright, M. J., Schmitter-Edgecombe, M., \& Woo, E. (2010). Verbal memory impairment in severe closed head injury: the role of encoding and consolidation. Journal of Clinical and Experimental Neuropsychology, 32(7), 728-736. https://doi.org/10.1080/13803390903512652

Received: May 23, 2020

Accepted: June 22, 2020

Published: June 27, 2020 